DE BEAUVOIR, Simone. Les inséparables. Paris, L'Herne, 2020.

\title{
Simone de Beauvoir, de Zaza ao feminismo ${ }^{1}$
}

"Se estou com lágrimas nos olhos esta noite, é porque você morreu ou é porque eu estou viva?2". Assim começa o livro inédito de Simone de Beauvoir, Les inséparables (As inseparáveis), redigido em 1954, mas publicado pela primeira vez em outubro de 2020, na França, pela sua filha adotiva, Sylvie Le Bon de Beauvoir.

Nesse romance biográfico, a filósofa volta entre nós no tempo ao narrar sua longa e profunda amizade com Elisabeth Lecoin, "Zaza", um dos encontros que mais marcaram sua juventude. $\mathrm{O}$ contexto da redação da obra se mostra, portanto, muito peculiar.

Escrito após mais de vinte anos de tormentos devido à morte prematura, brutal e misteriosa da sua brilhante amiga em 1929, aos vinte e um anos de idade, a pensadora opta, em 1954, por usar a escrita ficcional para se despedir de Zaza. Recorre, num estilo que lhe é próprio e que atravessa o conjunto da sua obra, à forma romance, a qual combina elementos biográficos, pensamento filosófico e crítica social.

Até então, o público conhecia o papel de Zaza na vida de Simone Beauvoir graças às suas memórias de juventude, que se encerraram com a morte brutal da amiga. "Juntas nós tínhamos lutado contra um destino hostil, e pensei por muito tempo que tinha pago o preço da minha liberdade com sua morte $3^{\prime \prime}$. À luz da redescoberta do romance hoje publicado, esse final toma uma dimensão mais plena.

\footnotetext{
1 Annabelle Bonnet, filósofa e doutora em sociologia pela École des Hautes Études en Sciences Sociales (EHESS) de Paris. Pesquisadora Associada da mesma École (CESPRA-EHESS-CNRS) e pós-doutoranda do Programa de pós-graduação em Política Social da Universidade Federal do Espírito Santo (PPGPS-UFES). Especialista nos temas "mulheres na filosofia", "história dos movimentos feministas", "história das mulheres" e "sociologia do gênero". Link para CV Lattes: http://lattes.cnpq.br/4916125651933085

2 DE BEAUVOIR, Simone. Les inséparables. Paris, L'Herne, 2020.Tradução livre do texto francês. Não existe, no momento, edição da obra em português.

3 Memórias de uma moça bem-comportada. Nova Fronteira, Rio de Janeiro, 2017 (1958).
} 
Afinal, por que duas mulheres da mesma idade, do mesmo meio e com uma igual vontade de viver e de ser livres, encontraram caminhos tão diferentes? Por que Simone sobreviveu à opressão contra as mulheres e Zaza não?

Através do destino trágico da amiga, Simone de Beauvoir oferece de fato um retrato da perda de sentido da vida das mulheres numa sociedade que as impede de existir por e para si próprias. Zaza, desprovida de controle sobre a sua própria existência, aparece assim como polo oposto do caminho percorrido por Simone. Enquanto a segunda rompe progressivamente com o seu meio social de origem, ganha independência financeira e se realiza na filosofia, Zaza se encontra cada vez mais presa ao universo social e familiar da elite francesa, penetrado pelos pensamentos irracionalistas e autoritários dos anos 1920, e dentro do qual as mulheres não são sujeitos de direito.

O livro constitui, neste sentido, uma fabulosa oportunidade de redescobrir a complexidade do pensamento beauvoiriano, a própria trajetória intelectual e pessoal de Simone de Beauvoir como filósofa feminista, bem como o seu processo de apropriação e de compreensão da questão da opressão específica às mulheres na sociedade burguesa, atravessada pela crise do liberalismo do início do século XX.

Simone de Beauvoir chegou a afirmar que, até escrever sobres as mulheres, não tinha sido incomodada no seu percurso de vida pelo fato de ser ela mesma uma mulher. "Minha feminidade nunca foi um obstáculo4", anotou assim em suas memórias em 1960. De fato, sabe-se que a sua obra mais famosa, O Segundo Sexo, publicada em 1949, aos quarenta e um anos de idade, constituiu, na trajetória intelectual da filósofa, uma virada fundamental. "Sei hoje em dia que, para me descrever, preciso afirmar: «Sou uma mulher»", concluiu. A partir deste passo, procurou dar prosseguimento a essa obra, aproximando-se do movimento comunista internacional, fundamentando publicamente a sua recusa do que chamou de "pensamento de direita" e apoiando, nos anos 1960-1970, os novos movimentos feministas.

Ao introduzir a história na sua reflexão filosófica sobre a questão dos sexos, rompeu teoricamente, como até então nenhuma filósofa francesa do seu meio o havia feito, com o princípio da eternidade das essências das categorias de feminino

${ }^{4}$ DE BEAUVOIR, Simone. A força da idade, Nova Fronteira, Rio de Janeiro, 2018 (1960). 
e de masculino. Herdeira, pela sua formação como filósofa e pelo ambiente intelectual da sua época, dos pensadores da modernidade Hegel e Marx, sem os quais a sua abordagem é historicamente inconcebível, Simone de Beauvoir superou também a sua própria sensibilidade.

"O fato é que nem as mulheres nem os homens estão satisfeitos uns com os outros", escreve na conclusão do segundo volume do Segundo Sexo. Cabe lembrar, ainda, que a filósofa termina esse livro recorrendo explicitamente a Marx, resgatando a ideia de que a dominação do homem sobre a mulher é expressão da sua própria degradação como ser humano. Dessa forma, conclui a autora, somente uma solidariedade inequívoca entre homens e mulheres poderá libertar o segundo sexo.

Mas, sabe-se também, através das suas próprias memórias, que suas facilidades de inserção profissional, bem com a sua legitimidade dentro do meio intelectual ao qual pertenceu, se deram menos a uma sorte do que a um conjunto de circunstâncias históricas e familiares que se imbricaram.

Dentre elas, cabe destacar um fato pouco comentado, mas de impacto direto sobre as possibilidades intelectuais de Simone de Beauvoir e que cumpre um papel central no romance recém-publicado: a Revolução Russa de 1917. De fato, ao abalar o mundo, afetou também o patrimônio da família De Beauvoir. Nascida em uma família rica descendente da ex-aristocracia francesa, o seu pai, cuja fortuna já tinha sido atingida pelas crises econômicas do início do século, havia investido a maior parte do seu dinheiro nos bancos da Rússia Tzarista, perdendo־o após a Revolução de 1917.

Arruinado, sem dote para poder casar suas filhas com homens do mesmo estatuto social, como era praxe na época, tomou a decisão, para garantir um futuro material para a suas filhas, de mandá-las estudar na universidade pública e, em seguida, buscar um trabalho. A sua desclassificação social provocou, em sequência, a ruptura com as convenções das famílias ricas tradicionais e ligadas à elite católica do país na época, segundo as quais as mulheres não deviam trabalhar, mas sim ter um papel de transmissoras do patrimônio familiar, de administradoras das suas casas e de representantes do seu meio nos encontros fora de casa. 
"Muitas vezes eu me congratulava, egoistamente, que os bolcheviques e a maldade da vida tivessem arruinado o meu pai: eu precisava trabalhar e os problemas que atormentavam "Zaza" não me desrespeitavam" (2020, p. 51), escreve nesse sentido no romance. Mesmo diante da crise do sistema liberal do início do século que atingiu toda a sociedade burguesa, a família de Zaza, por sua vez, não foi materialmente atingida. A partir de então, a família de Zaza passou a apoiar os pensamentos irracionalistas e autoritários, se refugiando cada vez mais nas ideias de extrema direita e nas convenções sociais e religiosas católicas mais rígidas, desconfiadas e intolerantes diante dos que pensavam diferente.

Dois acontecimentos se somaram a essa abertura para Simone de Beauvoir. Por um lado, uma carreira de professora para uma mulher de classe média, e às vezes de classe alta, tinha se tornado, à época, algo não apenas legalmente possível, mas bastante frequente e economicamente viável. Desde 1924, uma reforma do ensino igualara os diplomas femininos aos masculinos, até então desvalorizados e sinônimo de baixos salários.

Por outro lado, o acesso das mulheres ao ensino da filosofia, nos anos 1920, era fonte profunda de tensões nos meios universitários, pois neles se encontrava cristalizado um divisor de águas entre duas elites opostas no país, entre os liberais republicanos laicos e os antirrepublicanos católicos.

É, pois, em função deste conflito profundo que a mãe de Simone de Beauvoir, ardorosamente católica e antirrepublicana, tenta impedir a filha de estudar filosofia numa universidade pública, temendo pela sua saúde mental e pelo seu futuro como esposa e mãe. O pai, no entanto, já vivendo uma queda de sua condição de classe e distante das correntes católicas mais radicais, por reconhecer na filha o que chamou de "um cérebro de homem", apoiou a sua decisão sem briga, encerrando assim a polêmica familiar. A autorização do chefe de família constituiu, portanto, um passo fundamental no caminho intelectual de Simone de Beauvoir.

É exatamente nessas tensões dos anos 1920, acima expostas, que o novo romance de Simone de Beauvoir encontra o seu contexto mais imediato. São também essas circunstâncias descritas que permitem entender plenamente a vida de Zaza detalhada no romance e, junto a ela, parte do sofrimento de Simone de 
Beauvoir ao ver a sua amiga se afogando e, provavelmente também, compreender parte da sua decisão de romper com o seu meio social de origem.

De fato, o destino de Zaza é apresentado, no romance, como polo contrário ao de sua amiga Simone. Ambas ainda crianças, aos nove anos, quando se deu o primeiro encontro, Simone (Sylvie no romance) pouco se atreve a ultrapassar as regras impostas a uma menina bem-comportada, enquanto Zaza (Andrée no romance) é insolente, questiona a autoridade e as tradições religiosas católicas. Simone admira Zaza, como o descreve atentamente, por uma razão central: nela é contida uma personalidade, uma liberdade de pensar singular, que a pequena Simone não desenvolveu ainda. Zaza é um exemplo que deseja seguir, e a sua curiosidade encanta Simone.

Avançando nas suas criações, Simone segue, aos poucos, o modelo de Zaza. Torna-se mais revoltada, apesar de viver graves crises interiores, principalmente religiosas. Na adolescência, toma a decisão de não seguir o catolicismo, no qual não acredita mais, mas o esconde da família por muito tempo. Ao mesmo tempo, o comportamento do seu pai na hora de decidir seu destino de adulta abre para ela novos caminhos, que o encontro com o grupo de homens estudantes de filosofia da Sorbonne, dentre o qual o jovem Sartre, contribuirá a cristalizar para sempre.

Zaza, por sua vez, vive cada dia mais presa no seu meio social, tão convencional e hostil a qualquer cultura que não seja a já contida no seu círculo familiar. Brilhante escritora, excelente estudante de letras na Sorbonne, Zaza, ao contrário de Simone, quase nunca consegue escapar das tarefas familiares para poder estudar. O controle sobre as ações e o pensamento de Zaza se torna cada vez mais frequente e passa a ocorrer em cada pequeno momento da sua vida cotidiana. Cartas deixadas pela jovem estudante atestam essa dificuldade.

Além disso, muitos livros, conversas, amizades, aulas são proibidos pela própria mãe, e essa censura é descrita com atenção no romance. A filósofa toca aqui num tema privilegiado da literatura feminista da primeira parte do século XX, comum a vários dos seus outros romances, mas também presente na obra de uma pensadora como Virginia Woolf. Zaza não tem privacidade autorizada e nem espaço próprio. O seu tempo inteiro, bem como os seus pensamentos, se encontram 
controlados pela sua mãe, que a obriga, ademais, a revelar todas as suas reflexões, sob ameaça da jovem estar em pecado.

Qualquer possibilidade de autonomia é seguida por uma punição. "Para ser perdoada por seus estudos, suas leituras e nossa amizade, ela se empenhava em cumprir de maneira irrepreensível o que Madame Gallard chamava de seus deveres sociais" (2020, pp. 52-53). Zaza precisa compensar sua revolta, até passar a interiorizar um sentimento de culpa muito grande. Nesse momento do romance, Simone de Beauvoir tem um cuidado peculiar ao descrever como, devagar, o sentimento de culpa vai se sobrepondo ao sentimento de liberdade, deixando Zaza em crises interiores permanentes, que chegam a mexer com a sua própria personalidade. Qualquer opinião contrária à opinião familiar se torna fonte de um sentimento de impureza e de traição.

Nos seus últimos anos de vida, o controle sobre a sua própria vida é quase inexistente. Os pais a proíbem de ver sua amiga Simone, mas também de casar com o seu grande amor, o filósofo Maurice Merleau Ponty. Zaza vive sob ameaças constantes de ter que entrar no convento ou de ser casada com um homem que não escolheu e que não ama. No mesmo ano em que este drama ocorre, 1929, Simone de Beauvoir, por sua vez, continua à procura de outras saídas. Afasta-se do seu meio familiar conservador, rompe explicitamente com a religião católica, passa no concurso do ensino de filosofia e conquista sua independência financeira, passando a viver, sozinha, num pequeno quarto em Paris.

Zaza acompanha o quanto pode cada vitória da sua amiga, plenamente consciente das suas conquistas. Mas vive cada vez mais distante do tipo de vida escolhido por Simone. Ela não tem mais o direito de sair da casa dos pais até adoecer, um dia, de uma forma muito rápida e inexplicada até não acordar mais, sem que Simone de Beauvoir tivesse tempo de se despedir.

“Andrée morreu afogada por essa brancura" (2020, p. 92), escreve a filósofa, sublinhando a hipocrisia na qual, ao se falar de moral e de dever das mulheres, obrigaram, na verdade, a sua amiga a abandonar-se. $\mathrm{O}$ encontro consigo própria se tornou, para a amiga, impossível, e só chegou a se realizar na morte. Ao mesmo tempo amiga real, lembrança do passado e personagem literário, Zaza se torna, portanto, nesta obra, símbolo do sufocamento psíquico e físico das mulheres pela 
sociedade burguesa, esmagadora das subjetividades até a asfixia à qual não sobreviverá, e que a filósofa nunca mais deixará de combater e denunciar. 